\title{
THE EFFECT OF BOREDOM PRONENESS, IMPULSIVENESS AND SENSATION SEEKING TO DRIVER SPEEDING BEHAVIOR
}

\author{
Leksmono Suryo Putranto ${ }^{1}$, Anissa Noor Tajudin², Sunu Bagaskara ${ }^{3}$ \\ ${ }^{1}$ Civil Engineering Department, Universitas Tarumanagara, Jakarta, Indonesia \\ ${ }^{2}$ Department of Civil and Environmental Engineering, Universitas Gajah Mada, Yogyakarta, Indonesia \\ ${ }^{3}$ Psychology Faculty, Universitas YARSI, Jakarta, Indonesia \\ *E-mail of corresponding author: leksmonop@ft.untar.ac.id
}

\section{Resume}

Speeding or driving above the speed limit might be conducted due to various reasons. This paper is intended to investigate whether there are certain underlying behaviors that trigger speeding in the various driving environment. Authors were investigating the effect of boredom proneness, impulsiveness and sensation seeking on driver speeding behaviors. They received 676 responses to our distributed online questionnaires mainly from Lampung, East Java, East Borneo, North Celebes and North Moluccas. A Structural Equation Modelling (SEM) was conducted for analysis. The result implies that the drivers with high sensation seeking, low boredom proneness and high impulsiveness tend to drive at high speed.

\section{Article info}

Received 10 October 2021

Accepted 17 December 2021

Online 10 February 2022

\section{Keywords:}

speeding

boredom proneness

impulsiveness

sensation seeking

structural equation modelling

\section{Introduction}

There are various types of traffic violations, like the violations are conducted to get convenience or to gain a benefit [1]. For example, red-light running, or forcing other road users to give way when in a rush or under time pressure, or running in the opposite direction to get a shortcut, or driving above the speed limit (assuming the speed limit is too low). A study by Moraldi et al. [2] observes rural road links in 3 different speed limits, i.e., less than $50 \mathrm{~km} / \mathrm{h}, 50$ to $100 \mathrm{~km} / \mathrm{h}$ and above $100 \mathrm{~km} / \mathrm{h}$. A driver is more likely to exceed the speed limit in a road link with the lowest speed limit.

The usual prototype of accident victims mostly found is young males [3]. People within the 15 to 44 years old age group accounted for $59 \%$ of fatality in highways globally. Moreover, $77 \%$ of the victim were males [4]. Young males were more susceptible to speeding caused by the pressure from their peers [5]. In general, males were more likely to conduct risky behavior [6-7], both emotional and ordinary violations. However, females are specifically more vulnerable to lapses [8].

This study was intended to observe the effect of sensation seeking, boredom proneness and impulsiveness on the tendency of risky behavior by speeding.

\section{Sensation seeking}

Yilmaz and Celik [9] used five criteria to assess driver behavior, i.e., driver risky behavior, driver obedience to speed regulations, driver awareness on a traffic accident, driver inclination to take a risk in traffic and driver who violates basic traffic rules. Research in risky driver behavior found that sensationseeking traits and safety behavior have an important role in risky driving [10]. Zuckerman [11] stated that sensation seeking (SS) is a trait characterized by the tendency to seek for sensation and new experience, varied and extreme and risk-taking desire, physically, socially, legally and financially.

Zuckerman (2007) [11], stated that sensationseeking trait is a biological trait that triggers someone with high sensation-seeking to undermine the risk or assume that the risk is the only way to enjoy a sensational experience. On the contrary, people with low sensation-seeking tend to judge that the situation is riskier and there is no benefit to taking the risk. Some studies show convincing findings of the correlation between sensation seeking and risky driving behaviors. Sensation seeking and its combination with the other traits (for example aggressive and anger traits) would be able to predict risk (Scott-Parker et al, 2013) [12]. 
It is found that sensation seeking positively correlates with risky driving behavior, Wong et al. (2010) [13]. This will be expressed by speeding, ignoring traffic lights, dangerous overtaking, illegal U-turn, driving in the opposite direction and failed to keep a safe distance from the other vehicles ahead. Car driving is a complex behavior and involves various factors. Driving safety is not only affected by the driver's internal factors but it involves external factors, as well, such as social and environmental factors. In this paper, the internal factors are sensation seeking, boredom proneness and impulsiveness.

Driver with high sensation-seeking tends to have high confidence that he or she got the ability to perform the risky behavior. This confidence is subjective and might not be the real ability. This will trigger him or her to conduct risky behavior more likely compared to the one with low sensation seeking, for example, when he or she decided to drive at a high speed. This behavior requires higher driving skills to ensure safe driving. This skill is required as a basis for decision-making in a relatively short time, especially considering various dangerous consequences he or she could face. The driver with high sensation-seeking also exaggerates assessment of these abilities and therefore potentially get involved in an accident. Jonah et al. (2001) [14] stated that sensation seeking increases dangerous driving patterns, such as aggressive driving (yelling at other drivers, keep horning, involved in a street race) and high-risk driving (dangerous overtaking, speeding, red-light running, etc.).

Jonah [15] conducted a study on 40 research works regarding the relationship between sensation seeking and driver behavior. It was found that there was a relationship between sensation seeking and three types of dangerous driving behavior, i.e., drunk driving, unbelted driving and speeding. He found that in most cases, the correlation coefficients were between 0.3 and 0.4. He also found that sensation seeking had a significant correlation with violations and accidents. In general, he concluded that $10 \%$ to $15 \%$ of the variance in risky driving behavior is caused by sensation seeking.

\section{Boredom proneness}

The best definition of boredom is hesitant to a repeated experience in any form, routine tasks, or boring people and extreme anxiety in a condition when impossible to run away from determination and passion and relatively low dissatisfaction associated with the less stimulated situation, [16].

Boredom proneness is defined as a tendency to experience boredom and low involvement and personal enthusiasm and in general less sufficient interest in life and the future (Sundberg et al, 1991) [17]. Boredom proneness is an interesting aspect and complicated in human psychology affecting human life negatively in various ways. Boredom proneness has been proven to have a relationship with a mental health problem and also a dysfunctional personal character, which can affect physical health problems.

According to Kass et al. (2003) [18] boredom proneness significantly affects the ability to keep interest and concentration involving in activity and inability to be present in the activity. Wallace et al. (2003) [19] found that boredom proneness was an important indicator for the cognitive failure of a driver. So, in a monotonous situation (e.g., in a long straight and flat section on the freeway), the cognitive ability of a driver deteriorates. According to Teoh et al. (2020) [20], people with boredom proneness tend to postpone their sleeping time. There is an association between boredom proneness with the inability to manage life, e.g., insufficient sleep time. Postponing sleep time may cause an accumulation of required sleep. On a long term it may trigger sleep deprivation.

Boredom proneness can change someone's mood when driving. Boredom proneness can also cause dangerous sleepiness when driving, operating heavy machinery, conducting surgery, etc. According to Bustan (2007) [21], there were 5 factors related to a traffic accident, i.e. drivers, passengers, road users, vehicles and road facilities. It was found that $75 \%$ was caused by humans (supported by boredom proneness), $5 \%$ by vehicles, $5 \%$ by road conditions, $1 \%$ by environmental conditions. A driver was also asked to limit his/ her speed to minimize the traffic accidents.

\section{Impulsiveness}

An impulsive personality tends to act without thinking. Cheng et al. (2015) [22] compared impulsive behavior between 2 groups of taxi drivers (who had and had no traffic violation records in Hong Kong). Each group consists of 15 drivers. Drivers with traffic violation records tend to choose risky judgment which is impulsive personality character.

Anger can trigger someone to express impulsive behavior, 2006) [23]. This shows that angry individuals can conduct risky behavior without rational judgment (impulsive).

\section{Method}

The data collection was conducted online on 676 respondents. The original plan was to recruit 150 respondents in each of the 5 targeted provinces (Lampung, East Java, East Borneo, North Celebes and North Moluccas) to get representation from West, Central and East Indonesia. These also represent 5 major islands (Sumatera, Java, Borneo, Celebes and Moluccas Islands). However, authors could not control the spread of online survey, at the end of the survey 
Table 1 Measurement of the propensity of speeding under certain driving environment

\begin{tabular}{|c|c|c|}
\hline Variable Name & Description & Driving Environment \\
\hline SpeedOption1 & I Often Speeding on the Downward section. & \\
\hline SpeedOption $2 *$ & I Am Not Speeding at a Road with Limited Lighting & \\
\hline SpeedOption $3^{*}$ & I Am Not Speeding in Residential Area & \\
\hline SpeedOption $4 *$ & I Am Not Speeding in a Curve & \\
\hline SpeedOption5 & $\begin{array}{l}\text { On a Multilane Road, I Tend to Drive at a High } \\
\text { Speed. }\end{array}$ & \\
\hline SpeedOption6 & $\begin{array}{l}\text { In a Low Volume Road, I Tend to Drive at a High } \\
\text { Speed }\end{array}$ & \\
\hline SpeedOption $7 *$ & $\begin{array}{l}\text { I Am Not Speeding, on the Road with Many Heavy } \\
\text { Vehicles }\end{array}$ & \\
\hline SpeedOption8 & I Often Speed in a Rainy Road. & \\
\hline SpeedOption9* & I Am Not Speeding in Mountainous Road & \\
\hline SpeedOption $10^{*}$ & I Am Not Speeding in an Undivided Road & \\
\hline SpeedOption11 & I Often Speed on a Smooth Road & \\
\hline
\end{tabular}

* Item indicated by $(*)$ means reverse question (item with different direction with other items) 
period they received 127 responds from Lampung, 120 responds from East Java, 131 responds from East Borneo, 151 from North Celebes and 55 from North Moluccas or altogether 584 from targeted provinces. The rest 92 responds were spread in the area surrounding the targeted provinces. For example, 42 respondents were from Greater Jakarta, 5 respondents from West Java (outside Greater Jakarta), each 4 respondents were from South Sumatra and West Sumatra, 1 respondent from each Aceh, Bengkulu and Riau Islands near Lampung. There were 6 respondents from Central Java, 4 respondents from Yogyakarta and 1 respondent from each Bali, West Nusa Tenggara and East Nusa Tenggara near East Java. There were 2 respondents from South Borneo and 1 respondent from West Borneo near East Borneo. There were 6 respondents from South Celebes, 3 respondents from Gorontalo and 1 from Central Celebes near North Celebes. Finally, there were 7 respondents from West Papua near North Moluccas.

The online questionnaire contains 5 main parts. The first part was the general data. The general data consists of questions regarding gender, age, marital status, place of birth, current address, monthly expenses and weekly frequency of driving.

The second part was to measure Sensation Seeking (SS) using the short version of the SS questionnaire, [24]:

a. BSSS1 I want to visit various unfamiliar places,

b. BSSS2 I feel anxious if stay at home too long

c. BSSS3 I would like to conduct scary things.

d. BSSS4 I would like to conduct spontaneous travel, without planned routes and activities.

e. BSSS5 I would like to be a friend of people with unpredictable thoughts.

f. BSSS6 I would like to try bungee jumping, skydiving, or other challenging activities.

g. BSSS7 I want to have a new and fun experience although illegal. likely).

The responses were from 1 (very unlikely) to 5 (very

The third part was to measure Boredom Proneness (BP) using the short version of the BP questionnaire, [25]:

a. SBPS1 I often found myself in a deadlock and do not know what to do.

a. SBPS2 I feel difficult to cheer myself b. SBPS3 I did many repeated and monotonous things.

c. SBPS4 It requires more stimulation to become more advanced compared to the others.

d. SBPS5 I am not excited about what I do.

e. SBPS6 In various situation, I feel difficult to find an interesting thing to do or to observe.

f. SBPS7 In most of my time, I am only sitting, doing nothing.

The fourth part was to measure Impulsiveness (I) using Barratt Impulsiveness Scale, [26]:

b. AIS1 I do not pay attention.

c. AIS2R I can control myself (R).

d. AIS3R I am easily concentrated (R).

e. AIS4R I am a careful thinker (R).

f. AIS5R I keep thinking (R).

g. AIS6 I act without thinking.

h. AIS7 I say something without thinking.

i. AIS8 I act without planning.

j. AIS9 I act suddenly.

k. AIS10R I plan a task carefully (R).

l. AIS11R I plan my trip in advance (R).

m. AIS12R I plan a job with a clear future (R).

n. AIS13R I am a future-oriented person (R).

Item indicated by $(R)$ means reverse question (item with different direction with other items)

The fifth part was to measure the propensity of speeding under certain driving environments as described in Table 1.

The response for part 2 to part 4 was from 1 (very unlikely), 2 (unlikely), 3 (neutral), 4 (likely, and 5 (very likely). Structural equation modelling (SEM) was used for analysis.

\section{Respondent profile}

From the 677 respondents, there were 421 $(62 \%)$ male and the rest $255(38 \%)$ were female. The respondent's ages were between 16 and 67 years old with a mean age of 29 years old and standard deviation of the age of 12 years old. As the consequences of the relatively young mean age, most of the respondents $(66 \%)$ were single. There were only $32 \%$ married respondents and $2 \%$ widows or widowers. The highest monthly expenses (36\%) were more than 3 million rupiahs (around USD

Table 2 Summary of the Sensation Seeking Data

\begin{tabular}{clcc}
\hline \multicolumn{1}{c}{ Variable } & \multicolumn{2}{c}{ Mariable Values } \\
\hline Name & Description & 3.65 & Standard Deviation \\
\hline BSSS1 & Visit Unfamiliar Places & 3.13 & 0.86 \\
BSSS2 & Anxious if Stay at Home & 2.50 & 1.05 \\
BSSS3 & Conduct Scary Things & 3.20 & 0.96 \\
BSSS4 & Conduct Spontaneous Travel & 2.92 & 1.13 \\
BSSS5 & Unpredictable Thought Friend & 3.00 & 0.93 \\
BSSS6 & Try Challenging Activities & 2.37 & 1.28 \\
BSSS7 & New and Fun Experience & 1.07 \\
\hline
\end{tabular}


$210)$. In the other monthly expenses, $35 \%$ of respondents spent less than 1 million rupiahs (around USD 70) and $29 \%$ spent between 1 to 3 million rupiahs (USD 70-USD 210). Most of the respondents (47\%) drive cars 1-2 times a week, followed by more than 4 times a week (35\%) and lastly, $18 \%$ of respondents drive cars 3-4 times a week.

\section{Summary of the data}

The summary of the Sensation Seeking data is shown in Table 2. Visit unfamiliar places was the most common sensation-seeking behavior.
Summary of the Boredom Proneness data is shown in Table 3. Conducting repeated and monotonous things was the most common boredom proneness behavior. Sharing the same mean (3.18), requiring more stimulation to become more advanced compared to the others was the most common boredom proneness behavior, as well.

The summary of the Impulsiveness data is shown in Table 4. "I act suddenly" was the most common impulsive behavior. Items with $(*)$ had reversed scores.

The summary of the Speed Option data is shown in Table 5. Speeding in low-volume roads was the most

Table 3 Summary of the Boredom Proneness Data

\begin{tabular}{clcc}
\hline \multicolumn{1}{c}{ Variable } & & Variable Values \\
\hline Name & \multicolumn{1}{c}{ Description } & Mean & Standard Deviation \\
\hline SBPS1 & Deadlock & 2.70 & 0.97 \\
SBPS2 & Difficult to Cheer Myself & 2.52 & 1.00 \\
SBPS3 & Repeated and Monotonous & 3.18 & 0.97 \\
SBPS4 & Needs More Stimulation & 3.18 & 1.02 \\
SBPS5 & Difficult to Find Interesting Thing & 2.47 & 0.91 \\
SBPS6 & I am not excited about what I do & 2.70 & 0.96 \\
SBPS7 & Sitting Doing Nothing & 2.18 & 0.93 \\
SBPS8 & New and Fun Experience & 2.34 & 0.84 \\
\hline
\end{tabular}

Table 4 Summary of the Impulsiveness

\begin{tabular}{clcc}
\multicolumn{1}{c}{ Variable } & \multicolumn{1}{c}{ Variable Values } \\
\hline Name & \multicolumn{1}{c}{ Description } & Mean & Standard Deviation \\
\hline AIS1 & I do not Pay Attention & 2.25 & 0.82 \\
AIS2 $^{*}$ & I Can Control Myself & 2.18 & 0.77 \\
AIS3 $^{*}$ & I Am Easily Concentrated & 2.47 & 0.78 \\
AIS4 $^{*}$ & I Am a Careful Thinker & 2.42 & 0.75 \\
AIS5* $^{*}$ & I Keep Thinking. & 2.35 & 0.83 \\
AIS6 & I Act without Thinking & 2.21 & 0.81 \\
AIS7 & I Say Something without Thinking & 2.24 & 0.85 \\
AIS8 & I Act without Planning & 2.37 & 0.88 \\
AIS9 & I Act Suddenly & 2.66 & 0.85 \\
AIS10* & I Plan a Task Carefully & 2.36 & 0.74 \\
AIS1 $*$ & I Plan My Trip in Advance & 2.34 & 0.81 \\
AIS12* & I Plan a Job with a Clear Future & 2.03 & 0.76 \\
AIS13* & I Am a Future-Oriented Person & 1.97 & 0.75 \\
\hline
\end{tabular}

Table 5 Summary of the Speed Option data

\begin{tabular}{clcc}
\hline \multicolumn{1}{c}{ Variable } & \multicolumn{2}{c}{ Variable Values } \\
\hline Name & \multicolumn{1}{c}{ Description } & Mean & Standard Deviation \\
\hline SpeedOption1 & I Often Speed on the Downward section. & 2.37 & 0.89 \\
SpeedOption2* $^{*}$ & I Am Not Speeding at a Road with Limited Lighting & 2.21 & 0.98 \\
SpeedOption3* & I Am Not Speeding in Residential Area & 1.97 & 0.85 \\
SpeedOption4* & I Am Not Speeding In a Curve & 2.05 & 0.89 \\
SpeedOption5 & On a Multilane Road, I Tend to Drive at a High Speed. & 3.27 & 1.04 \\
SpeedOption6 & In a Low Volume Road, I Tend to Drive in a High Speed & 3.79 & 0.90 \\
SpeedOption7* & I Am Not Speeding, in a Road with Many Heavy Vehicles & 2.20 & 0.89 \\
SpeedOption8 & I Often Speed in a Rainy Road. & 2.08 & 0.84 \\
SpeedOption9* & I Am Not Speeding in Mountainous Road & 2.26 & 0.95 \\
SpeedOption10* & I Am Not Speeding in an Undivided Road & 2.43 & 0.82 \\
SpeedOption11 & I Often Speed on a Smooth Road & 3.71 & 0.86 \\
\hline
\end{tabular}


Table 6 Measurement Model and Composite Reliability (CR)

\begin{tabular}{|c|c|c|c|c|}
\hline Constructs & Items & $\beta$ & $\mathrm{p}$ & $\mathrm{CR}$ \\
\hline \multirow[t]{11}{*}{ Speed Option } & SpeedOption1 & 0.42 & $<.001$ & \multirow{11}{*}{0.76} \\
\hline & SpeedOption2* & 0.54 & $<.001$ & \\
\hline & SpeedOption $3^{*}$ & 0.49 & $<.001$ & \\
\hline & SpeedOption4* & 0.73 & $<.001$ & \\
\hline & SpeedOption5 & 0.11 & 0.011 & \\
\hline & SpeedOption6 & $<0.00$ & 0.943 & \\
\hline & SpeedOption7* & 0.61 & $<.001$ & \\
\hline & SpeedOption8 & 0.37 & $<.001$ & \\
\hline & SpeedOption9* & 0.61 & $<.001$ & \\
\hline & SpeedOption $10^{*}$ & 0.53 & $<.001$ & \\
\hline & SpeedOption11 & 0.05 & 0.199 & \\
\hline \multirow[t]{7}{*}{ Sensation Seeking } & BSSS1 & 0.24 & $<.001$ & \multirow{7}{*}{0.74} \\
\hline & BSSS2 & 0.40 & $<.001$ & \\
\hline & BSSS3 & 0.6 & $<.001$ & \\
\hline & BSSS4 & 0.61 & $<.001$ & \\
\hline & BSSS5 & 0.61 & $<.001$ & \\
\hline & BSSS6 & 0.48 & $<.001$ & \\
\hline & BSSS7 & 0.56 & $<.001$ & \\
\hline \multirow[t]{8}{*}{ Boredom Proneness } & SBPS1 & 0.58 & $<.001$ & \multirow{8}{*}{0.81} \\
\hline & SBPS2 & 0.61 & $<.001$ & \\
\hline & SBPS3 & 0.46 & $<.001$ & \\
\hline & SBPS4 & 0.58 & $<.001$ & \\
\hline & SBPS5 & 0.68 & $<.001$ & \\
\hline & SBPS6 & 0.68 & $<.001$ & \\
\hline & SBPS7 & 0.65 & $<.001$ & \\
\hline & SBPS8 & 0.39 & $<.001$ & \\
\hline \multirow[t]{13}{*}{ Impulsiveness } & AIS1 & 0.48 & $<.001$ & \multirow{13}{*}{0.83} \\
\hline & AIS2* & 0.42 & $<.001$ & \\
\hline & AIS3* & 0.47 & $<.001$ & \\
\hline & AIS4* & 0.43 & $<.001$ & \\
\hline & AIS5* & 0.10 & 0.023 & \\
\hline & AIS6 & 0.57 & $<.001$ & \\
\hline & AIS7 & 0.53 & $<.001$ & \\
\hline & AIS8 & 0.54 & $<.001$ & \\
\hline & AIS9 & 0.43 & $<.001$ & \\
\hline & AIS10* & 0.45 & $<.001$ & \\
\hline & AIS11* & 0.37 & $<.001$ & \\
\hline & AIS12* & 0.41 & $<.001$ & \\
\hline & AIS13* & 0.4 & $<.001$ & \\
\hline
\end{tabular}

*=Reversed Scores 
common speeding option. Items with $(*)$ had reversed scores.

\section{Results}

There are three steps of data analysis: (1) measurement model (2) structural model and (3) testing the role of sensation seeking, boredom proneness and impulsiveness to speed option.

\subsection{Measurement model}

Confirmatory factor analysis (CFA) was conducted using Jamovi version 1.8 software to test the relationship between constructs in the proposed research model, [27]. The CFA was conducted using the maximumlikelihood (ML) estimation procedure to estimate model parameters, [28].

The measurement model was tested based on the loading factors of each item towards tested latent constructs and reliability coefficient. The results show that all the tested items have significant loading factors towards each latent construct ( $p<0.01$ ), except for items 6 and 11 on the speed option variable and item 5 on the impulsiveness. Therefore, the three items were not included in the further analysis to reach a model with a better fit. The reliability of the questionnaire was tested based on the composite reliability coefficient. The usual threshold for composite reliability is 0.7 [28]. The analysis showed that the measurement in this study complies with recommended composite reliability (Table 6 ). Therefore, the measurement scales in this study were satisfactory to be used for the SEM analysis.

\subsection{Structural model analysis}

The SEM analysis was used to test the fitness of the structural model with the obtained data. To assess model goodness-of-fit, Kline (2010) [29] and Hair et al. [28] recommended several fitness indices to be used. Those indices include Root Mean Square Residuals (RMSR) $<0.10$, Root Mean Square Error of Approximation (RMSEA) $<0.08$, Comparative Fit Index $(\mathrm{CFI})>0.90$, Goodness-of-fit Index (GFI) $>0.90$ and Tucker-Lewis Index (TLI) $>0.90$.

\subsection{The role of sensation seeking, boredom proneness and impulsiveness to speed option}

The analysis using the Jamovi software shows that the structural model complies with the recommended fitness criteria $(\mathrm{RSMR}=0.06 ; \mathrm{RMSEA}=0.04$; $\mathrm{CFI}=0.91 ; \mathrm{GFI}=0.91 ; \mathrm{TLI}=0.90)$. The path analysis shows that the speed option significantly affected by the three observed constructs, i.e., sensation seeking ( $\beta=$ $0.21, \mathrm{p}<0.01)$, boredom proneness $(\beta=-0.34, \mathrm{p}<0.01)$ and impulsiveness $(\beta=0.61, \mathrm{p}<0.01)$, with $\mathrm{R}^{2}=0.27$ (Figure 1).

\section{Conclusion and recommendation}

Sensation seeking, boredom proneness and impulsiveness can explain $27 \%$ variability of the driving speed option/ choice. The result implies that the drivers with high sensation seeking, low boredom proneness and high impulsiveness tend to drive at high speed.

It is recommended to use the result of this study

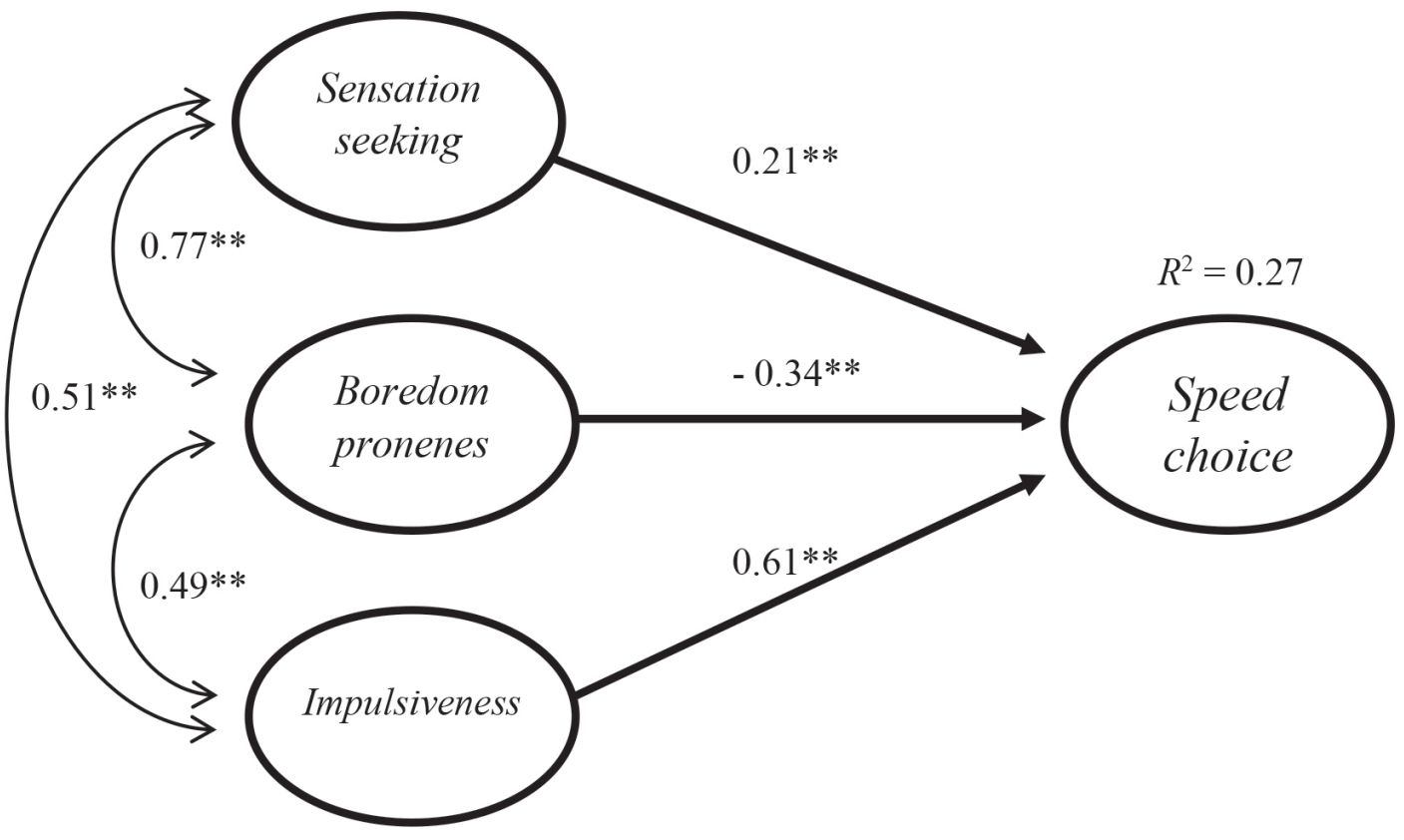

Figure 1 The Structural Model; ${ }^{* *} p<0.01$ 
as a basis for the better design of road safety campaign again speeding. Further analysis needs to be done using the same dataset to understand the effect of gender, age, driving frequency and monthly expenses on driving at a high speed.

\section{Acknowledgments}

The authors acknowledge the Ministry of Research \& Technology for financing this research.
We also acknowledge Dr. Ir. Rahayu Sulityorini and Zenia F. Saraswati, MPWK from Itera, Prof. Dr. Ir. Ria A. A. Soemitro and Mr. Anggoro Dias from ITS, Dr. Ir. Tiopan H.M. Gultom and Mr. Halid from Unmul, Ir. Theo K. Sendow, MT and Miss Andini from Unsrat and Dr. Ir. Sabaruddin and Miss Nurul Izzah from Unkhair for their help in data collection in Lampung, East Java, West Borneo, North Celebes and North Moluccas. We also acknowledge Untar for providing additional grant for this research.

\section{References}

[1] PARKER, D., MANSTEAD, A. S. R., STRADLING, S. G., REASON, J. T. Determinants of intention to commit driving violations. Accident Analysis and Prevention [online]. 1992, 24, p. 117-131 [accessed 2020-10-10]. ISSN 0001-4575. Available from: https://doi.org/10.1016/0001-4575(92)90028-H

[2] MORADI, A., MOTEVALIAN, S. A., MIRKOOHI, M., MCKAY, M. P., RAHIMI-MOVAGHAR, V. Exceeding the speed limit: prevalence and determinants in Iran. International Journal of Injury Control and Safety Promotion [online]. 2013, 20(4), p. 307-312 [accessed 2020-10-11]. ISSN 1745-7300, eISSN 1745-7319. Available from: https:// doi.org/10.1080/17457300.2012.692693

[3] SARMA, K. M., CAREY, R. N., KERVICK, A. A., BIMPEH, Y. Psychological factors associated with indices of risky, reckless and cautious driving in a national sample of drivers in the Republic of Ireland. Accident Analysis and Prevention [online]. 2013, 50, p. 1226-1235 [accessed 2020-10-11]. ISSN 0001-4575. Available from: https:// doi.org/10.1016/j.aap.2012.09.020

[4] World Health Organization. Global status report on road safety 2013: supporting a decade of action. Luxemburg: World Health Organization, 2015. ISBN 9789241564564.

[5] MOLLER, M. An explorative study of the relationship between lifestyle and driving behavior among young drivers. Accident Analysis and Prevention [online]. 2004, 36(6), p. 1081-1088 [accessed 2020-10-10]. ISSN 00014575. Available from: https://doi.org/10.1016/j.aap.2004.03.003

[6] BACHOO, S., BHAGWANJEE, A., GOVENDER, K. The influence of anger, impulsivity, sensation-seeking and driver attitudes on risky driving behavior among post-graduate university students in Durban, South Africa. Accident Analysis and Prevention [online]. 2013, 55, p. 67-76 [accessed 2020-10-10]. ISSN 0001-4575. Available from: https://doi.org/10.1016/j.aap.2013.02.021

[7] ROIDL, E., FREHSE, B., OEHL, M., HOGER, R. The emotional spectrum in traffic situations: results of two online studies. Transportation Research Part F: Traffic Psychology and Behavior [online]. 2013, 18, p. 168-188 [accessed 2020-10-12]. ISSN 1369-8478. Available from: https://doi.org/10.1016/j.trf.2012.12.009

[8] SHI, J., BAI, Y., YING, X., ATCHLEY, P. Aberrant driving behaviors: a study of drivers in Beijing. Accident Analysis and Prevention [online]. 2010, 42, p. 1031-1040 [accessed 2020-10-12]. ISSN 0001-4575. Available from: https://doi.org/10.1016/j.aap.2009.12.010

[9] YILMAZ, V., CELIK, H. E. Risky driving attitudes and self-reported traffic violations among Turkish drivers: the case of Eskisehir. Dogus Universitesi Dergisi. 2011, 7(1), p. 127-138 [accessed 2020-10-11]. ISSN 1302-6739.

[10] GONZÁLEZ-IGLESIAS, B., GOMEZ-FRAGUELA, J. A., LUENGO-MARTIN, M. A. Driving anger and traffic violations: gender differences. Transportation Research Part F: Traffic Psychology and Behavior [online]. 2012, 15(4), p. 404-412 [accessed 2020-10-11]. ISSN 1369-8478. Available from: https://doi.org/10.1016/j.trf.2012.03.002

[11] ZUCKERMAN, M. Sensation seeking and risky behavior. Washington, DC: American Psychological Association, 2007. ISBN 1591477387.

[12] SCOTT-PARKER, B., HYDE, M. K., WATSON, B., KING, M. J. Speeding by young novice drivers: What can personal characteristics and psychosocial theory add to our understanding? Accident Analysis and Prevention [online]. 2013, 50, p. 242-250 [accessed 2021-09-20]. ISSN 0001-4575. Available from: https://doi.org/10.1016/j. aap.2012.04.010

[13] WONG, J. T., CHUNG, Y. S., HUANG, S. H. Determinants behind young motorcyclists` risky riding behavior. Accident Analysis and Prevention [online]. 2010, 42, p. 275-281 [accessed 2021-09-22]. ISSN 0001-4575. Available from: https://doi.org/10.1016/j.aap.2009.08.004

[14] JONAH, B. A., THIESSEN, R., AU-YEUNG, E. Sensation seeking, risky driving and behavioral adaptation. Accident Analysis and Prevention [online]. 2001, 33, p. 679-684 [accessed 2021-09-22]. ISSN 0001-4575. Available from: https://doi.org/10.1016/s0001-4575(00)00085-3 
[15] JONAH, B. A. Sensation seeking and risky driving: a review and synthesis of the literature. Accident Analysis and Prevention [online]. 1997, 29, p. 651-665 [accessed 2021-09-22]. ISSN 0001-4575. Available from: https://doi. org/10.1016/s0001-4575(97)00017-1

[16] MIKULAS, W., VODANOVICH, S. The essence of boredom. The Psychological Record. 1993, 43, p. 3-12 [accessed 2021-09-23]. ISSN 0033-2933.

[17] SUNDBERG, N., LATKIN, C., FARMER, R., SAOUD, J. Boredom in young adults, gender and cultural comparisons. The Annals of the American Academy of Political and Social Science [online]. 1991, 503(1), p. 122-136 [accessed 2021-03-16]. ISSN 0022-0221, eISSN 1552-5422. Available from: https://doi.org/10.1177/0022022191222003

[18] KASS, S., WALLACE, J., VODANOVICH, S. Boredom proneness and sleep disorders as predictors of adult attention deficit scores. Journal of Attention Disorders [online]. 2003, 7(2), p. 83-91 [accessed 2021-09-25]. ISSN 1087-0547, eISSN 1557-1246. Available from: https://doi.org/10.1177/108705470300700202

[19] WALLACE, J., VODANOVICH, S., RESTINO, B. predicting cognitive failures from boredom proneness and daytime sleepiness scores: an investigation within military and undergraduate samples. Personality and Individual Differences [online]. 2003, 34(4), p. 635-644 [accessed 2021-09-25]. ISSN 0191-8869. Available from: https://doi.org/10.1016/S0191-8869(02)00050-8

[20] TEOH, A. N., OOI, E. Y. E., CHAN, A. Y. Boredom affects sleep quality: the serial mediation effect of inattention and bedtime procrastination. Personality and Individual Differences [online]. 2021, 171, 110460 [accessed 202109-25]. ISSN 0191-8869. Available from: https://doi.org/10.1016/j.paid.2020.110460

[21] BUSTAN, M. N. Epidemiology of non-infectious disease / Epidemiologi Penyakit Tidak Menular (in Indonesian). Jakarta: Rineka Cipta, 2007. ISBN 9789795188926.

[22] CHENG, A. S. K., TING, K. H., LIU, K. P. Y., BA, Y. Impulsivity and risky decision making among taxi drivers in Hong Kong: an event-related potential study. Accident Analysis and Prevention [online]. 2016, 95, p. 387-394 [accessed 2020-10-13]. ISSN 0001-4575. Available from: https://doi.org/10.1016/j.aap.2015.12.021

[23] DIGIUSEPPE, R., TAFRATE, R. C. Understanding anger disorders. Oxford: Oxford University Press, 2006. ISBN 0195170792.

[24] HOYLE, R. H., STEPHENSON, M. T., PALMGREEN, P., LORCH, E. P., DONOHEW, R. L. Reliability and validity of a brief measure of sensation seeking. Personality and Individual Differences [online]. 2002, 32, p. 401-414 [accessed 2021-03-16]. ISSN 0191-8869. Available from: https://doi.org/10.1016/S0191-8869(01)00032-0

[25] STRUK A. A., CARRIERE J. S. A, CHEYNE J. A., DANCKERT J. A. Short boredom proneness scale: development and psychometric properties. Assessment [online]. 2017, 24(3), p. 346-359 [accessed 2021-03-16]. ISSN 1073-1911, eISSN 1552-3489. Available from: https://doi.org/10.1177/1073191115609996

[26] PATTON J. H., STANFORD M. S., BARRATT E. S. Factor structure of the Barratt impulsiveness scale. Journal of Clinical Psychology [online]. 1995, 51(6), p. 768-774 [accessed 2021-03-15]. ISSN 0021-9762, eISSN 1097-4679. Available from: https://doi.org/ 10.1002/1097-4679(199511)51:6<768::aid-jclp2270510607>3.0.co;2-1

[27] The Jamovi Project. Jamovi Version 1.8. Computer software [online]. 2021. Available from: https://www.jamovi. org

[28] HAIR, J. F., BLACK, W. C., BABIN, B. J., ANDERSON, R. E. Multivariate data analysis. 7. ed. Upper Saddle River, New Jersey: Prentice Hall, 2010. ISBN 0138132631.

[29] KLINE, R. B. Promise and pitfalls of structural equation modelling in gifted research. In: Methodologies for conducting research on giftedness. 1. ed. Washington, DC: American Psychological Association, 2010. ISBN 1433807149 , p. 147-169. 